\title{
VIABILITY OF WOOD DECAYING FUNGAL MYCELIUM AFTER MICROWAVE RADIATION OF BAMBOO CULM
}

\author{
Pawan Kumar Poonia ${ }^{1, \star}$ \\ https://orcid.org/0000-0002-1906-718X \\ Shivaklara R Deepa ${ }^{2}$ \\ Manish Kumarl \\ Anil Kumar ${ }^{3}$
}

\begin{abstract}
The present study was carried out to evaluate the effects of microwave (MW) radiation on viability of wood decaying fungi. The white rot (Trametes versicolor) and brown rot (Rhodonia placenta) fungi were grown on bamboo culm-samples. The mycelium growths were observed in controlled as well as microwave treated samples. The results showed that the viability of fungi decreased according to the applied MW time. This study proved the ability of the microwaves and exposure time MW3 (180 seconds) to kill the fungal colonies and do not allow for the growth of fungal spores, means the rate of growth of fungal colonies is inversely proportional to time of microwave exposure.
\end{abstract}

Keywords: Bamboo culm, decay, fungal colonies, microwave treatment, Rhodonia placenta, Trametes versicolor, viability.

\section{INTRODUCTION}

The chief economic product of forest is wood i.e., utilized for various purposes such as construction, furniture, door, window, among other. Failure of wood in service through biodeterioration is a prime cause of user dissatisfaction. Although many types of organisms deteriorate wood, the greatest damage is from fungi and insect, and to a minor extent- from bacteria (Highley et al. 1994, Schmidt 2006).

The most important and potent wood-decay fungi are white and brown-rot. For decay to occur, the minimum moisture content is slightly below the fibre saturation range (average $25-30$ percent) and the temperature between about $2{ }^{\circ} \mathrm{C}$ and $45^{\circ} \mathrm{C}$ (Pasanen et al. 1992, Highley et al. 1994, Morris and Winandy 2002, Schmidt 2006). Stienen et al. (2014) showed mycelia growth on wood with $17,4 \%$ moisture content and mass loss over $2 \%$ at $24,6 \%$ moisture content. Oxygen must also be available because decay fungi are aerobic organisms. Finally, a suitable substrate, such as wood, must be present to nourish the fungus. Interference with any of these requirements stops the decay process. 
Bamboo has a low natural durability (Liese and Kumar 2003). As a biological material like wood, it is susceptible to degrade by different organism such as insect and fungi (Schmidt et al. 2011). Bamboo deterioration can be controlled by impregnation with chemicals, but due to toxic behaviours of these chemicals, namely, pentachlorophenol, copper chrome arsenate, creosote and several others many countries have banned their use for wood preservation (Poonia and Tripathi 2016). Public concern about the use of synthetic chemicals concomitantly with significantly tightened environmental regulations have created demands for the development of alternative methods for the chemical wood protection that we can go for substitute like microwave treatment.

Microwave (MW) radiation is an innovative method for improving wood permeability, treatability and the drying rate of wood. This method can also be capable of inactivating microbial contaminations not only on exposed surfaces but inside them as well (Poonia and Tripathi 2018). It can result in reducing or stopping colonization of microbiologically contaminated surfaces and thus can decrease the number of agents contributing to the adverse effects on growing environment of fungi (Chipley 1980).

The majority of the experiments i.e., effects of microwave radiation were conducted on bacteria and yeasts. There are several studies however some studies on basidiomycetes. For example, Baumann-Ebert and Körner (2013) used portable MW devices to kill the most important European indoor rot fungus Serpula lacrymans (brown rot) within thick wooden beams. Plarre et al. (2013) performed corresponding experiments with $S$. lacrymans and larvae of the beetles Anobium punctatum and Hylotrupes bajulus. There are already national standards for the use of MW treatment against wood-destroying organisms. For example, the German standard DIN 68800-4 (2012) allows the use of MW treatment against insects in buildings, however not against fungi due to less research results.

The present work was carried out to evaluate the effect of MW on viability and decay of future wood decaying fungi.

\section{MATERIALS AND METHODS}

\section{Preparation of bamboo culm specimens}

Bamboo (Bambusa vulgaris Schrad.) culms were procured from Sirsi (Lat $14^{\circ} 61^{\prime} \mathrm{N}$, Long $74^{\circ} 85^{\prime}$ E), Karnataka, India and converted into small clear specimens of size $2 \mathrm{~cm} \times 2 \mathrm{~cm}$. The defect free specimens were randomly selected and further smoothen by sand paper to remove the silica layer.

\section{Preparation of culture media}

A nutrient medium (i.e., PDA) consists of $4 \mathrm{~g} / 1$ potato starch, $20 \mathrm{~g} / 1$ glucose and $15 \mathrm{~g} / \mathrm{l}$ agar was prepared in an Erlenmeyer bottle. The Erlenmeyer was then plugged with cotton, wrapped with foil and autoclaved at $0,21 \mathrm{MPa}$ and $121^{\circ} \mathrm{C}$ for 20 minutes.

\section{Inoculation of fungi}

The effect of microwave radiation was tested against the white rot fungus (Trametes versicolor (L.: Fr.) Pilat) and the brown rot species Rhodonia placenta (Fr.) Niemelä, K.H. Larss. \& Schigel. The fungi were inoculated on potato dextrose agar (PDA) in Petri dishes under a laminar air flow. Inoculated plates were then kept at $25^{\circ} \mathrm{C} \pm 2{ }^{\circ} \mathrm{C}$ and $75 \% \pm 5 \% \mathrm{RH}$ for 7 days for growth. After the growths of mycelial, spore suspension was prepared according to IS 4873 (2008).

Bamboo culm samples were exposed to fungal attack by placing them in the petri dishes in which there are actively growing cultures of $T$. versicolor and $R$. placenta. The spore suspension was sprayed over the bamboo samples for aerial contact with fungal mycelium. Then, the petri dishes were further kept at $25^{\circ} \mathrm{C} \pm 2{ }^{\circ} \mathrm{C}$ and $75 \% \pm 5 \% \mathrm{RH}$ for growth of fungi on bamboo samples. After initiation of growth, the petri dishes were kept in MW oven for different times. 


\section{Microwave treatment}

MW oven with maximum output power $900 \mathrm{~W}$ at frequency $2450 \mathrm{MHz}$ was used. Treatments were done at different times i.e., $60 \mathrm{~s}$ (T-1), $120 \mathrm{~s}$ (T-2) and $180 \mathrm{~s}$ (T-3). Six replicates in each treatment. The controls were maintained simultaneously. After MW treatment, inoculated bamboo samples were further kept at $25^{\circ} \mathrm{C} \pm 2{ }^{\circ} \mathrm{C}$ and $70 \% \pm 4 \% \mathrm{RH}$. The results were recorded after 21 days in terms of per cent surface covered by the test fungi over the bamboo samples (Tripathi et al. 2009). The percent inhibition in growth of fungi was calculated by using visual scores and by weight loss (Poonia et al. 2015).

\section{Weight loss and visual scores assessment of fungal growth}

The bamboo blocks were weighed before $\left(\mathrm{W}_{1}\right)$ and after 21 days of inoculation of fungi $\left(\mathrm{W}_{2}\right)$. In MW treated specimens the weight after MW treatment were considered as initial weight. The efficacy of treatment was categories on basis of weight loss and surface coverage by test fungi. Weight loss was calculated as follows (Equation 1):

$$
\text { Weight loss method }(\%)=\frac{W_{1}-W_{2}}{W_{1}} \times 100
$$

Where, $\mathrm{W}_{1}=$ Weight of Petri dish containing bamboo blocks before inoculation of fungi $(\mathrm{g})$

$\mathrm{W}_{2}=$ Weight of Petri dish containing bamboo blocks after 21 days inoculation of fungi $(\mathrm{g})$

\section{Statistical analysis}

Statistical analysis was conducted using SPSS 16 version (IBM 2007). Effect of MW treatment time on fungi growth/viability were compared using variance analysis (ANOVA) and the Duncan homogeneity test at $95 \%$ confidence interval.

\section{RESULTS AND DISCUSSIONS}

The results revealed that the control samples exhibited higher weight loss i.e., 48,09 and 47,66 percentage in white (T. versicolor) and brown rot (R. placenta) fungi respectively. Further, it was observed that the $60 \mathrm{~s}$ showed less effect on growth with weight loss of 30,16 and 30,37\% (T. versicolor and R. placenta, respectively) as shown in Figure 1. Whereas, the weight loss percentage were significantly decreased as increased in MW treatment duration in both the fungi at $(\mathrm{P} \leq 0,05)$ level. The MW treatment time with specific frequency plays an important role in the effect of the microwaves which is time-dependent, where the intensity of the weight loss carried by fungal infection is inversely proportional to the total absorbed microwave energy.

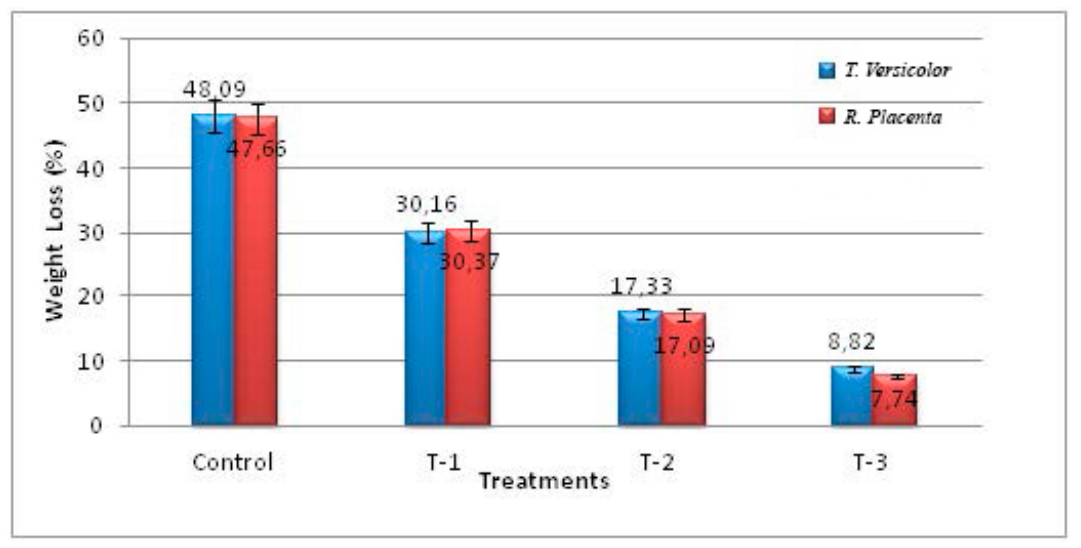

Figure 1: Effect of microwave treatment on weight loss of Bamboo blocks/samples. 
The results in term of surface coverage by test fungi i.e., $T$. versicolor and $R$. placenta over bamboo samples containing PDA medium are shown in Table 1 and Figure 2.

Table 1: Effect of microwave treatment on bamboo sample surface coverage of wood decaying fungi.

\begin{tabular}{|c|c|c|c|c|}
\hline \multirow{2}{*}{$\begin{array}{c}\text { Sample } \\
\text { No. }\end{array}$} & \multirow{2}{*}{ Treatment } & \multicolumn{2}{|c|}{ Surface coverage (\%) } & \multirow{2}{*}{ Efficacy of treatment } \\
\cline { 3 - 4 } & & T.versicolor (Tv) & R.placenta (Rp) & \\
\hline 1 & Control & $100^{\mathrm{a}}$ & $100^{\mathrm{a}}$ & Growth complete (> 75\%) \\
\hline 2 & T-1 & $32,50^{\mathrm{b}}$ & $40,50^{\mathrm{b}}$ & Growth moderate (25\% to $50 \%)$ \\
\hline 3 & T-2 & $10,70^{\mathrm{C}}$ & $8,75^{\mathrm{c}}$ & Growth Little (5\% to $25 \%)$ \\
\hline 4 & T-3 & $0,00^{\mathrm{d}}$ & $0,00^{\mathrm{d}}$ & Growth none (0\%) \\
\hline
\end{tabular}

Mean square error of Tv and $\mathrm{Rp}$ is 6,34 and 6,74 respectively at $(\mathrm{p} \leq 0,05)$ level. Different letters denote significantly different groups.

It was observed that T-1 treatment (60 s of exposure) showed less effect on growth of both fungi, the inhibition was 67,50 and $59,50 \%$ (T. versicolor and $R$. placenta) respectively. While the results shown that after T-3 treatment (180 s of exposure) the fungal growth were completely inhibited and the percentage of inhibition were $100 \%$ for both fungi as compare to controls. The viability of mycelium of both fungi were significantly decreased $(\mathrm{P} \leq 0,05)$ after MW exposure. The reason behind inhibition of fungal growth may be due to heat generated by microwaves create steam pressure within the wood/micro-organism due to presence of moisture exerted the killing effect on fungi (Gorny et al. 2007).

The microwaves treatment at frequency $2450 \mathrm{MHz}$, with high energy and for a sufficiently long period of time, their thermal effect is most likely dominant to kill fungal mycelium (Al-Mayah and Ali 2010). However, at lower duration treatment, the killing effect of microwave radiation was significantly decreased and happened only after a prolonged period of irradiation, because of a lower transformation of microwave energy to heat. Some other studies showed that the extent of killing of microorganisms was correlated with the moisture content of the experimental specimens. In contrast, when microorganisms were irradiated with microwaves at temperatures lower than the thermal destruction level; various effects were observed, from killing to enhanced growth (Kuchma et al. 1992, Ahmed et al. 2015). Hence, the study concluded that microwave radiation method has better possibilities of application using wood of building constructions (Gorny et al. 2007). Covering a larger space with microwave field create the possibility to obtain a more homogeneous temperature distribution on the wood subjected to reduce the growth of fungus. So that using of microwave radiation treatment we can reduce the wood deterioration.

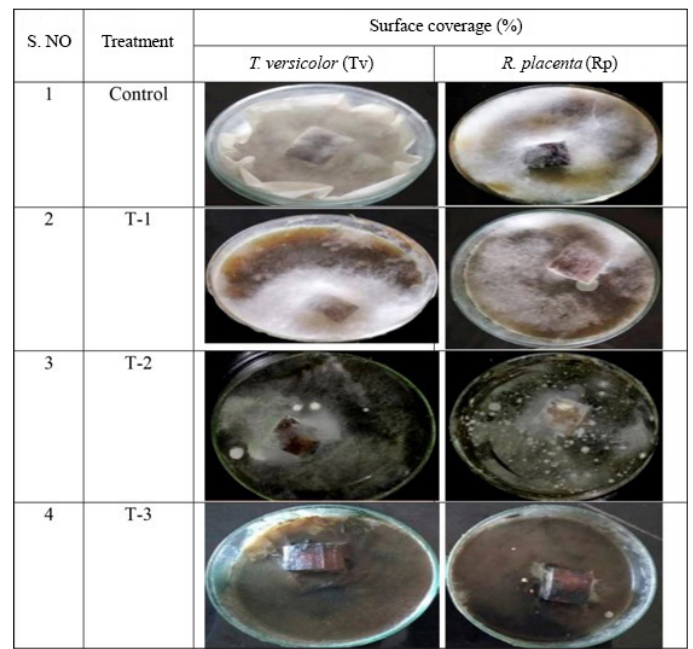

Figure 2: Surface coverage by wood decaying fungi after MW treatment. 
However, it should be considered that surface coverage of wood or bamboo culm samples are no sure indicator for degradation of the respective wood tissues. There are several wood-decay fungi which produce severe wood degradation with no or only meager surface mycelium, for example, the brown cellar fungus Coniophora puteana in buildings (Schmidt 2006).

\section{CONCLUSIONS}

The present study was carried out to evaluate the viability of wood decaying fungi growing on bamboo culm samples against microwave treatment. The study revealed that the microwave play a significant role in controlling the fungal growth/viability. Hence, this study suggests that to apply this technology at pilot scale can control fungal growth in building materials.

\section{REFERENCES}

Al-Mayah, A.A.; Ali, E.T. 2010. Mobile microwave effect on bacterial antibiotic sensitivity. Basrah Journal of Veterinary Research 10(2): 89-103. https://www.iasj.net/iasj?func=fulltext\&aId=55052.

Baumann-Ebert, S.; Körner, J. 2013. Integrierter Holzschutz unter Einsatz des Mikrowellenverfahrens am Beispiel einer klassischen Stadtvilla mit Befall durch den Echten Hausschwamm. EIPOS, Fraunhofer IRB Verlag: Stuttgart, 28-57.

Ahmed, L.T.; Majeed, A.D.; Salhi S.A. 2015. The effect of mobile waves on the growth of pathogenic Fungi. International Journal of Current Microbiology and Applied Sciences 4(11): 838-842. https://www.ijcmas.com/vol-4-11/Luma\%20T.\%20Ahmed,\%20et\%20al.pdf.

Chipley, J.R. 1980. Effects of microwave irradiation on microorganisms. Advances in Applied Microbiology 26: 129-145. https://doi.org/10.1016/S0065-2164(08)70333-2.

DIN. 2012. Wood preservation - Part 4: Curative treatment of wood destroying fungi and insects and refurbishment. DIN 68800-4. 2012. German standard, Beuth Verlag GmbH. https://dx.doi.org/10.31030/1857875

Gorny R.L.; Mainelis G.; Wlazlo, A.; Niesler A.; Lis, D.O.; Marzec, S.; Siwinska, E.; Ludzen-Izbinska, B.; Harkawy, A.; Kasznia-Kocot, J. 2007. Viability of fungal spores after microwave radiation of building materials. Ann Agric Environ med 14(2): 313-324. http://yadda.icm.edu.pl/yadda/element/bwmeta1. element.agro-article-0e631aa2-0e2b-4bb4-9e90-37930a3ae8d2

Highley, T.L.; Clausen, C.A.; Croan, S.C.; Green, F.; Illman, B.L.; Micales, J.A. 1994. Research on biodeterioration of wood, 1987-1992. I. Decay mechanisms and biocontrol. Research Paper FPLRP-529. Department of Agriculture, Forest Service, Forest Products Laboratory: Madison, WI, USA. https://www.osti.gov/biblio/6776653.

IBM. 2007. SPSS Modeler 16.0. SPSS Inc.: Chicago, IL, USA. https://www.ibm.com/support/pages/downloading-ibm-spss-modeler-160

Indian Standards. IS. 2008. Methods of laboratory testing of wood preservatives against fungi. IS. 4873. 2008. Bureau of Indian Standards: Marg New Delhi, India.

Kuchma, T.N.; Alipov, E.D.; Samoilenko, L.L.; Lystsov, V.N. 1992. Comparative analysis of mechanisms of the modification of microorganism viability under the effect of UHF heating and hyperthermia. Radiobiologiia 32(6): 881-886. https://pubmed.ncbi.nlm.nih.gov/1494658/ 
Liese, W.; Kumar, S. 2003. Bamboo preservation compendium. Centre for Indian Bamboo Resource and Technology: India. $231 \mathrm{p}$.

Morris, P.I.; Winandy, J.E. 2002. Limiting Conditions for Decay in Wood Systems. In Proceedings IRG Annual Meeting, IRG/WP 02-10421. The International Research Group on Wood Protection: Cardiff, South Wales, UK, pp. 1-11

Pasanen, A.L.; Juutinen, T.; Jantunen, M.J.; Kalliokoski, P. 1992. Occurrence and moisture requirements of microbial growth in building materials. Int Biodeterioration \& Biodegradation 30(4): 273-283. https://doi.org/10.1016/0964-8305(92)90033-K

Plarre, R.; Steinbach, S.; Roland, U.; Trommler, U.; Hoyer, C. 2013. Thermische Bekämpfungsverfahren im Holzschutz mit elektromagnetischen Wellen. EIPOS, Fraunhofer IRB Verlag: Stuttgart, 107-115.

Poonia, P.K.; Devi, L.A.; Tripathi, S. 2015. The efficacy of methanolic extract of Eucalyptus tereticornis sm. Leaves against wood decaying fungi. Indian Forester 141(8): 869-872. http://www.indianforester.co.in/index.php/indianforester/article/view/77004

Poonia, P.K.; Tripathi, S. 2016. Moisture related properties of Eucalyptus tereticornis after thermal modification. Journal of Tropical Forest Science 28(2): 153-158. https://www.jstor.org/stable/43799218

Poonia, P.K.; Tripathi, S.2018. Effect of microwave heating on $\mathrm{pH}$ and termite resistance of Pinus roxburghii wood. Maderas-Cienc Tecnol 20(3): 499 - 504. http://dx.doi.org/10.4067/S0718-221X2018005031901.

Schmidt, O. 2006. Wood and tree fungi. Biology, damage, protection, and use. Springer-Verlag: Berlin Heidelberg. 336p. https://doi.org/10.1007/3-540-32139-X.

Schmidt, O.; Wei, D.S.; Liese, W.; Wollenberg, E. 2011. Fungal degradation of bamboo samples. Holzforschung 65(6): 883-888. https://doi.org/10.1515/HF.2011.084.

Stienen, T.; Schmidt, O.; Huckfeldt, T. 2014. Wood decay by indoor basidiomycetes at different moisture and temperature. Holzforschung 68(1): 9-15. https://doi.org/10.1515/hf-2013-0065.

Tripathi, S.; Rawat, K.; Dhyani, S.; Pant, H. 2009. Potential of Lantana camara Linn. weed against wood destroying fungi. Indian Forester 135(3): 403-411. http://www.indianforester.co.in/index.php/indianforester/article/view/361. 